\title{
Rapid, routine evaluation of left ventricular diastolic function and left ventricular filling pressures during cardiac magnetic resonance imaging
}

\author{
Padmini Varadarajan* and Raas Pai
}

Address: Loma Linda University Medical Center, Loma Linda, CA, USA

* Corresponding author

from 13th Annual SCMR Scientific Sessions

Phoenix, AZ, USA. 21-24 January 2010

Published: 21 January 2010

Journal of Cardiovascular Magnetic Resonance 2010, I2(Suppl I):P265 doi:I0.I I86/1532-429X-I2-SI-P265

This abstract is available from: http://jcmr-online.com/content/I2/SI/P265

(c) 2010 Varadarajan and Pai; licensee BioMed Central Ltd.

\section{Introduction}

Left ventricular (LV) diastolic function and LV filling pressure is clinically important and is routinely assessed by echocardiography. Cardiac MRI (CMR) is increasingly used in practice. We investigated the feasibility of incorporating this in routine CMR examination.

\section{Methods}

A GE HDx 3 T system with 8 channel cardiac coil was used for CMR examination. Mitral and pulmonary vein flows were obtained in 130 consecutive patients. The short axis slice with mitral valve was then used to acquire phase contrast images with VENC of $1 \mathrm{~m} / \mathrm{sec}$. Next the long axis of the LV showing the pulmonary vein, usually the right upper was acquired. An in-plane image of the pulmonary vein was obtained. Next a through plane phase contrast image of the pulmonary vein was obtained with a VENC of $80 \mathrm{~cm} / \mathrm{sec}$. Phantom images at the same mitral and pulmonary vein levels were obtained at the end of the study to correct for background noise.

\section{Results}

Analyzable signals were obtained in all 117 patients with an average of 5 additional minutes. Mitral flow velocity signals were classified as normal, abnormal relaxation, pseudonormal and restrictive patterns using the standard criteria (figure 1). Pulmonary vein 'AR' wave duration relative to mitral ' $\mathrm{A}$ ' wave duration was used to differentiate normal from pseudo-normal. Following patterns were noted: 19 abnormal relaxation, 1 pseudonormal, 1 restric- tive, 1 atrial fibrillation with high filling pressure, 95 normal. Of the 26 with an echocardiogram within a month of CMR, 25 had fully concordant filling patterns.

\section{Conclusion}

1) Rapid, routine CMR assessment of LV diastolic function and LV filling pressure is feasible. 2) It correlates well with echocardiography and should be part of a complete CMR examination. 
Mitral (top panel) and Pulmonary vein flow (bottom panel)

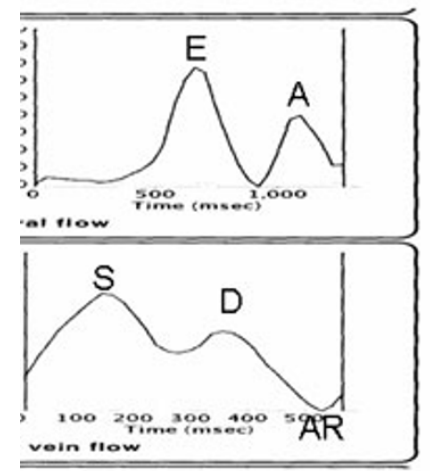

Normal Pattern

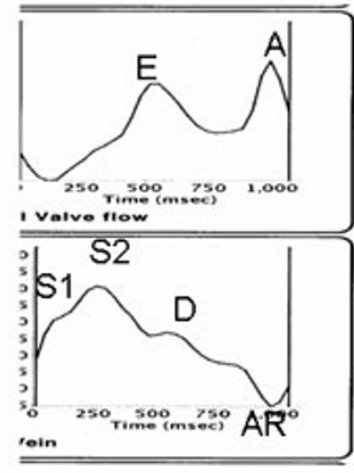

Abnormal Relaxation



Restrictive Pattern

Figure I

Publish with Biomed Central and every scientist can read your work free of charge

"BioMed Central will be the most significant development for disseminating the results of biomedical research in our lifetime. " Sir Paul Nurse, Cancer Research UK

Your research papers will be:

- available free of charge to the entire biomedical community

- peer reviewed and published immediately upon acceptance

- cited in PubMed and archived on PubMed Central

- yours - you keep the copyright
BioMedcentral 